\title{
HUBUNGAN TINGKAT PENGETAHUAN DENGAN SIKAP REMAJA AWAL TERHADAP PERUBAHAN FISIK MASA PUBERTAS DI MTS PUI CIWEDUS KUNINGAN TAHUN 2019
}

\section{RELATIONSHIPS OF KNOWLEDGE LEVELS WITH TEENAGERS ATTITUDES TO PHYSICAL CHANGE IN PUBERTAS PERIOD AT MTS PUI CIWEDUS KUNINGAN 2019}

\author{
Fera Riswidautami Herwandar \\ februari_rabu.fera88@yahoo.co.id
}

\begin{abstract}
ABSTRAK
Masa remaja dibedakan menjadi masa remaja awal usia 10-13 tahun, masa remaja tengah usia 14-16 tahun serta remaja akhir pada usia 17-19 tahun. Kesehatan yang paling utama pada masa remaja adalah kesehatan reproduksi. Perubahan yang menandakan bahwa remaja sudah memasuki tahap kematangan organ seksual yaitu dengan tumbuhnya organ seks sekunder. Metode jenis penelitian ini menggunakan analitik dengan menggunakan rancangan cross sectional, populasi dalam penelitian ini 67 responden dengan menggunakan teknik pengambilan total sampling, pengumpulan data menggunakan data primer dan sekunder. Instrumen yang digunakan kuesioner, uji analisis yang digunakan Chi-Square. Hasil analisis univariat, pengetahuan baik 24 responden $35,8 \%$, pengetahuan cukup 33 responden $49,3 \%$, pengetahuan kurang 10 responden $14,9 \%$, sikap positif 49 responden $73,1 \%$, sikap negatif 18 responden $26,9 \%$. Sedangkan analisis bivariat, penelitian ini menunjukan terdaapat hubungan signifikan antara pengetahuan dengan sikap remaja awal tentang perubahan fisik masa pubertas di MTs PUI Ciwedus Timbang Kecamatan Cigandamekar Kabupaten Kuningan Tahun 2019 dengan nilai $p$ value $=0,007$. Pada penelitian ini, terdapat hubungan antara pengetahuan dengan sikap remaja awal terhadap perubahan fisik masa pubertas di MTs PUI Ciwedus Timbang Kecamatan Cigandamekar Kabupaten Kuningan Tahun 2019. Saran bagi remaja awal untuk terus meningkatkan pengetahuan tentang pubertas baik melalui pelajaran dari sekolah maupun mencari informasi melalui internet, buku, ataupun sumber informasi lainnya.
\end{abstract}

Kata Kunci : Pengetahuan, Sikap, Pubertas

\begin{abstract}
Adolescence is divided into early adolescence aged $10-13$ years, middle adolescence aged 14-16 years and late adolescence at 17-19 years of age. The most important health in adolescence is reproductive health. Changes that indicate that adolescents have entered the sexual organ maturity stage, namely by the growth of secondary sex organs. This type of research method using analytic using cross sectional design, the population in this study was 67 respondents using total sampling techniques, data collection using primary and secondary data. The instrument used was a questionnaire, and the analytical test used ChiSquare. The results of univariate analysis, good knowledge of 24 respondents $35.8 \%$, sufficient knowledge of 33 respondents $49.3 \%$, less knowledge of 10 respondents $14.9 \%$, positive attitude of 49 respondents $73.1 \%$, negative attitudes of 18 respondents $26.9 \%$. While bivariate analysis, this study shows that there is a significant relationship between knowledge
\end{abstract}


and attitudes of early adolescents about the physical changes of puberty at MTs PUI Ciwedus Timbang in Cigandamekar District, Kuningan Regency in 2019 with $p$ value $=0.007$. In this study, there is a relationship between knowledge and attitudes of early adolescents towards the physical changes of puberty at MTs PUI Ciwedus Timbang, Cigandamekar District, Kuningan Regency in 2019. Suggestions for early adolescents to continue to improve knowledge about puberty both through lessons from school and seeking information via the internet books, or other sources of information.

\section{Keywords : Attitude, Knowledge, Puberty}

\section{PENDAHULUAN}

Manusia dalam perkembangannya melewati beberapa fase, salah satunya adalah masa remaja. Menurut World Health Organizasation (WHO), remaja adalah yang berusia 10-24 tahun. Masa remaja adalah masa peralihan dari anakanak ke dewasa. Pada masa ini terjadi banyak perubahan dan masalah, yang jika tidak cepat ditangani akan menjadi masalah yang berkepanjangan dan berdampak serius. Salah satu masalah remaja yang memerlukan perhatian adalah masalah kesehatan, dimana kesehatan merupakan elemen penting manusia untuk dapat hidup produktif. Remaja yang sehat adalah remaja yang produktif sesuai dengan tingkat perkembangannya. ${ }^{1}$

Masa remaja adalah masa yang begitu penting dalam hidup manusia, karena terjadi proses awal kematangan organ reproduksi pada manusia yang disebut masa pubertas. Masa peralihan dari masa anak-anak menuju dewasa. Pada masa ini terjadi perubahan dalam hal fisik maupun psikis. Masa remaja dibedakan menjadi masa remaja awal usia 10-13 tahun, masa remaja tengah usia 14-16 tahun serta remaja akhir pada usia 17-19 tahun. Kesehatan yang paling utama pada masa remaja adalah kesehatan reproduksi. Masa remaja merupakan proses perjalanan hidup dari masa anakanak yang terbebas oleh tanggungjawab sampai pada masa dewasa yang memiliki berbagai tanggungjawab. ${ }^{2}$
Pubertas merupakan suatu tahapan yang sangat penting bagi wanita. Periode pubertas akan terjadi perubahan dari masa anak-anak menjadi dewasa. Perubahan tersebut meliputi perubahan hormon, perubahan fisik, perubahan psikologi dan sosial. Pubertas merupakan proses perubahan ketidakmatangan fisik dan seksual menuju kematangan fisik dan seksual. Fase kematangan fisik dan seksual dapat membuat organ reproduksi seorang remaja dapat berfungsi untuk bereproduksi. ${ }^{2,3}$

Perubahan yang menandakan bahwa remaja sudah memasuki tahap kematangan organ seksual yaitu dengan tumbuhnya organ seks sekunder. Pertumbuhan organ seks sekunder dapat ditandai dengan pembesaran payudara, tumbuhnya rambut ketiak dan alat kemaluan, adanya jerawat, bau badan yang menyengat, pinggul membesar dan juga mulai berkembangnya beberapa organ vital yang siap untuk dibuahi. 3,4

Pola asuh orang tua banyak mempengaruhi sikap remaja sebagai orang yang dinggap penting dalam hidupnya, sehingga mempengaruhi sikap remaja dalam mempersiapkan dirinya menuju masa pubertas, mengenali ciri fisik, maupun perubahan masa pubertas yang akan memunculkan sikap positif maupun sikap negatif pada remaja. Sikap tersebut yang akan membentuk karakter diri remaja saat berada di lingkungan sekitarnya. ${ }^{5}$ 
Berdasarkan uraian di atas, didapat bahwa tingkat pengetahuan mengenai perubahan fisik pada masa pubertas juga dapat mempengaruhi sikap dan pola perilaku remaja. Oleh karena itu peneliti merasa perlu melakukan penelitian tentang hal tersebut. Hal ini penting karena dengan mengetahui sejauh mana perubahan yang sering terjadi dalam diri remaja akan mengambil sikap yang benar dalam menghadapi hal tersebut. Peneliti ingin mengetahui tingkat pengetahuan remaja mengenai perubahan fisik masa pubertas yang dialami oleh remaja itu sendiri.

\section{METODE}

Jenis penelitian yang digunakan adalah analitik yang bertujuan untuk mempelajari hubungan antara tingkat pengetahuan terhadap sikap remaja awal terhadap perubahan fisik pada masa pubertas di MTs PUI Ciwedus Timbang Kecamatan Cigandamekar Kabupaten Kuningan Tahun 2019.

Adapun populasi dalam penelitian ini adalah semua siswa kelas VII di MTs PUI Ciwedus yaitu berjumlah 74 responden.

Teknik pengambilan sampel dalam penelitian ini menggunakan teknik total sampling sehingga jumlah sample yang diambil sebanyak 74 responden. Pada penelitian ini variabel bebas dan variabel terikat menggunakan kuesioner. Observasi merupakan pengumpulan data dengan mengadakan pengamatan secara langsung kepada responden penelitian untuk mencari perubahan atau hal-hal yang akan diteliti.

\section{HASIL}

Berdasarkan hasil penelitian yang dilakukan di MTs PUI Ciwedus Timbang Kecamatan Cigandamekar Kabupaten Kuningan Tahun 2019, tentang hubungan antara tingkat pengetahuan dengan sikap remaja awal teradap perubahan fisik pada masa pubertas maka didapat hasil sebagai berikut :
Tabel 1 Distribusi Frekuensi Remaja Awal Berdasarkan Jenis Kelamin di MTs PUI Ciwedus Timbang Tahun 2019

\begin{tabular}{ccc}
\hline $\begin{array}{c}\text { Jenis } \\
\text { Kelamin }\end{array}$ & $\begin{array}{c}\text { Frekuensi } \\
\text { (F) }\end{array}$ & $\begin{array}{c}\text { Persentase } \\
(\%)\end{array}$ \\
\hline Perempuan & 36 & 53,7 \\
\hline Laki-laki & 31 & 46,3 \\
\hline Total & $\mathbf{6 7}$ & $\mathbf{1 0 0}$ \\
\hline
\end{tabular}

Sumber : Hasil Penelitian Tahun 2019

Tabel 1 menunjukkan bahwa dari 67 responden sebagian besar berjenis kelamin perempuan yaitu sebanyak 36 responden $(53,7 \%)$.

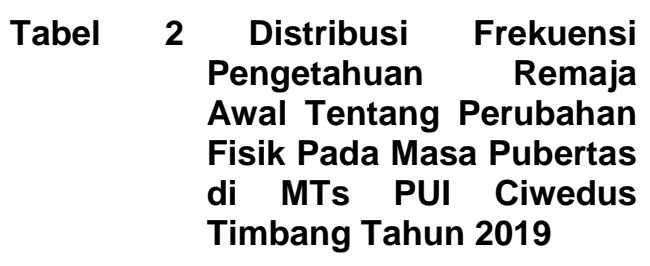

\begin{tabular}{ccc}
\hline $\begin{array}{c}\text { Tingkat } \\
\text { Pengetahuan }\end{array}$ & $\begin{array}{c}\text { Frekuensi } \\
\text { (F) }\end{array}$ & $\begin{array}{c}\text { Persentase } \\
\text { (\%) }\end{array}$ \\
\hline Tinggi & 24 & 35,8 \\
\hline Cukup & 33 & 49,3 \\
\hline Kurang & 10 & 14,9 \\
\hline Total & $\mathbf{6 7}$ & $\mathbf{1 0 0}$ \\
\hline
\end{tabular}

Sumber : Hasil Penelitian Tahun 2019

Berdasarkan tabel 2 dapat diketahui dari 67 responden sebagian besar berpengetahuan cukup yaitu sebanyak 33 responden $(49,3 \%)$.

Tabel 3 Distribusi Frekuensi Sikap Remaja Awal Tentang Perubahan Fisik Pada Masa Pubertas di MTs PUI Ciwedus Timbang Tahun 2019

\begin{tabular}{lcc}
\hline Sikap & $\begin{array}{c}\text { Frekuensi } \\
\text { (F) }\end{array}$ & $\begin{array}{c}\text { Persentase } \\
(\%)\end{array}$ \\
\hline Positif & 49 & 73,1 \\
\hline Negatif & 18 & 26,9 \\
\hline Total & $\mathbf{6 7}$ & $\mathbf{1 0 0}$ \\
\hline Sumber : Hasil Penelitian Tahun 2019
\end{tabular}

Tabel 3 menunjukkan bahwa dari 67 responden sebagian besar bersikap positif tentang perubahan fisik pada masa pubertas yaitu sebanyak 49 responden $(73,1 \%)$. 


$\begin{array}{llr}\text { Tabel } & 4 \begin{array}{c}\text { Hubungan } \\ \text { Pengetahuan Tingkat } \\ \text { dengan }\end{array} \\ \text { Sikap Remaja Awal } & \text { Terhadap Perubahan Fisik } \\ \text { Masa Pubertas di MTs PUI } \\ \text { Ciwedus Timbang Tahun } \\ 2019 \backslash\end{array}$

\begin{tabular}{|c|c|c|c|c|c|c|c|}
\hline \multirow{3}{*}{$\begin{array}{l}\text { Tingkat } \\
\text { Penge- } \\
\text { tahuan }\end{array}$} & \multicolumn{4}{|c|}{ Sikap } & \multirow{2}{*}{\multicolumn{2}{|c|}{ Total }} & \multirow{3}{*}{$\begin{array}{c}p \\
\text { value }\end{array}$} \\
\hline & \multicolumn{2}{|c|}{ Positif } & \multicolumn{2}{|c|}{ Negatif } & & & \\
\hline & $f$ & $\%$ & $f$ & $\%$ & $\mathbf{F}$ & $\%$ & \\
\hline Tinggi & 23 & 95,8 & 1 & 4,2 & 24 & 100 & \\
\hline Cukup & 20 & 60,6 & 13 & 39,4 & 33 & 100 & 0,007 \\
\hline Kura & 6 & 60,0 & 4 & 40,0 & 10 & 100 & \\
\hline
\end{tabular}

\section{Sumber : Hasil Penelitian Tahun 2019}

Berdasarkan tabel 4 di atas menunjukan bahwa dari 67 responden yang berpengetahuan tinggi yaitu sebanyak 23 responden (95,8\%) yang bersikap positif, yang berpengetahuan cukup yaitu sebanyak 20 responden $(60,6 \%)$ yang bersikap positif, dan yang berpengetahuan kurang 6 responden $(60, \%)$ yang bersikap positif. Berdasarkan hasil uji statistik didapatkan $p$ value $=0,007$ dengan batas kemaknaan 0,05 sehingga Ha diterima, kesimpulannya terdapat hubungan yang positif dan signifikan antara pengetahuan dengan sikap remaja awal tentang perubahan fisik pada masa pubertas di MTs PUI Ciwedus Timbang Tahun 2019. Hal ini artinya semakin tinggi tingkat pengetahuannya maka semakin positif sikap remaja awal tentang perubahan fisik pada masa pubertas.

\section{PEMBAHASAN}

Berdasarkan hasil penelitian yang diperoleh bahwa sebagian besar responden berpengetahuan cukup tentang perubahan fisik pada masa pubertas yaitu sebanyak 33 responden atau $49,3 \%$, disebabkan karena saat responden mendapatkan pelajaran dari sekolah responden tidak begitu memahami dengan baik hanya mendapatkan pelajaran dari sekolah tanpa mencari informasi dari sumber lain seperti internet atau buku dan terdapat beberapa siswa belum memiliki gadget.
Banyak faktor yang bisa mempengaruhi pengetahuan seseorang seperti pengalaman, keyakinan, fasilitas, dan sosial budaya. Pengetahuan dapat diperoleh melalui fakta, melihat dan mendengar, misalnya dengan membaca surat kabar, mendengarkan radio, menonton televisi, dan lain-lain. $6,7 \mathrm{Hal}$ ini sejalan dengan penelitian yang berjudul "Gambaran Tingkat Pengetahuan Remaja Awal 11-13 tahun tentang pubertas pada siswa-siswi kelas 5 dan kelas 6 di SDN Ngoto Sewon Bantul Yogyakarta Tahun 2011". Hasil penelitian tersebut menyebutkan bahwa tingkat pengetahuan siswa tentang perubahan fisik tergolong cukup $(45,2 \%)$. Karena siswa belum terlalu mempunyai keinginan untuk mencari informasi tentang pengertian pengetahuan pada masa pubertas. ${ }^{6}$

Berdasarkan analisis univariat diperoleh hasil bahwa responden yang bersikap positif tentang perubahan fisik masa pubertas yaitu sebanyak 49 responden atau $73,1 \%$. Responden yang berpengetahuan kurang sebanyak 18 responden atau $26,9 \%$. Hal ini lebih banyak dipengaruhi oleh kurangnya informasi yang didapatkan responden baik itu informasi dari segi telekomunikasi (handphone) maupun informasi dari lingkungan sekitar. Terutama dalam hal yang berhubungan dengan informasi kesehatan reproduksi dari faktor lingkungan sekitar. Terutama dalam hal yang berhubungan dengan informasi kesehatan reproduksi. Kurangnya informasi ini mengakibatkan responden merasa asing. Sikap adalah respon tertutup seseorang terhadap stimulasi atau objek tertentu. ${ }^{7,8} \mathrm{Hal}$ ini sepaham dengan hasil penelitian mengenai Pengetahuan Remaja Awal tentang Pubertas dengan Sikap Menghadapi Perubahan Fisik yang menunjukkan hasil bahwa sikap remaja awal dalam menghadapi perubahan pada masa pubertas tergolong positif $(57,6 \%)$.

Berdasarkan hasil uji statistik di MTs PUI Ciwedus Timbang Tahun 2019 diketahui semakin tinggi nilai pengetahuan maka semakin positif pula sikap siswa dalam 
menghadapi masa pubertas, hal ini sejalan dengan nilai perolehan chiSquare menunjukan nilai $p=0,007$ (< nilai a 0,05 ) yang artinya Ha diterima atau dengan kata lain terdapat hubungan yang bermakna antara tingkat pengetahuan terhadap sikap remaja awal pada masa pubertas.

Perubahan fisik pada masa pubertas mempengaruhi semua bagian tubuh, baik eksternal maupun internal, sehingga terus mempengaruhi keadaan fisik dan psikologis remaja. ${ }^{9}$ Meskipun akibatnya bersikap sementara, namun cukup menimbulkan perubahan dalam pola perilaku. Hal ini sejalan dengan penelitian mengenai hubungan Pengetahuan dengan Sikap Remaja Putri dalam Menghadapi Menarche di SMPN 2 Biau Kabupaten Buol". Hasil penelitian tersebut menyebutkan bahwa terdapat hubungan yang bermakna antara tingkat pengetahuan dengan sikap remaja pada masa pubertas. ${ }^{10}$

Berdasarkan hasil penelitian diperoleh bahwa responden yang berpengetahuan cukup sebagian besar bersikap positif tentang perubahan fisik masa pubertas yaitu sebanyak 49 responden atau 73,1 $\%$. Hal tersebut menunjukkan bahwa diperlukan bimbingan dan konseling dari pihak sekolah untuk meningkatkan pengetahuan tentang perubahan fisik pada masa pubertas.

Responden yang berpengetahuan cukup sebanyak 33 responden, 20 diantaranya memiliki sikap positif dan 13 memiliki sikap negatif. Dalam hal ini pengetahuan cukup sudah dalam kategori baik, akan tetapi masih banyak yang memiliki sikap negatif dikarenakan siswa tersebut sulit bergaul, pengaruh orang tua yang terlalu mengekang. Responden yang berpengetahuan baik sebanyak 24 responden, 23 diantaranya memiliki sikap positif dan 1 memiliki sikap negatif. Hal ini dikarenakan siswa tersebut memahami dengan baik pelajaran dari sekolah juga mencari informasi dari sumber lain seperti internet atau buku, akan tetapi ada siswa yang belum begitu memiliki keinginan untuk mencari sumber pengetahuan. Responden yang berpengetahuan kurang sebanyak 10 responden 4 memiliki sikap negatif, dan 6 memiliki sikap positif. Hal ini dikarenakan siswa sudah memiliki gadget dan orang tuanya yang memiliki pendidikan tinggi sehingga anak tersebut mudah mendapat informasi dari media sosial bahkan didikan orang tuanya.

\section{SIMPULAN DAN SARAN}

Berdasarkan hasil penelitian hubungan tingkat pengetahuan dengan sikap remaja awal terhadap perubahan fisik masa pubertas di MTs PUI Ciwedus Timbang Kecamatan Cigandamekar Kabupaten Kuningan Tahun 2019 maka penulis membuat kesimpulan sebagai berikut :

1. Gambaran remaja awal berdasarkan jenis kelamin sebagian besar berjenis kelamin perempuan yaitu sebanyak $36(53,7 \%)$ responden.

2. Tingkat pengetahuan remaja awal tentang perubahan fisik pada masa pubertas di MTs PUI Ciwedus Timbang Kecamatan Cigandamekar Kabupaten Kuningan Tahun 2019 berpengetahuan cukup yaitu sebanyak 33 (49,3\%) responden.

3. Sikap remaja awal tentang perubahan fisik masa pubertas di MTs PUI Ciwedus Timbang Kabupaten Kuningan Tahun 2019 bersikap positif yaitu sebanyak $49 \quad(73,1 \%)$ responden.

4. Terdapat hubungan yang positif dan signifikan antara tingkat pengetahuan dengan sikap remaja awal tentang perubahan fisik masa pubertas di MTs PUI Ciwedus Timbang Kabupaten Kuningan Tahun 2019 dengan nilai $p$ $=0,007$.

Melihat hasil penelitian tentang hubungan tingkat pengetahuan dengan sikap remaja awal terhadap perubahan fisik masa pubertas, maka penulis memberikan saran diantaranya :

1.Diharapkan remaja yang berpengetahuan cukup ataupun kurang agar lebih meningkatkan wawasan dan pengetahuan baik belajar melalui internet, buku, ataupun penyuluhan dari puskesmas 
agar remaja lebih paham tentang perubahan fisik atau sikap yang terjadi pada masa pubertas.

2. Bagi MTs PUI Ciwedus Timbang Melalui penelitian ini diharapkan pihak institusi dapat bekerjasama dengan tenaga kesehatan guna mengadakan kegiatan penyuluhan atau membentuk suatu wadah organisasi yang terkait dengan kesehatan reproduksi pada masa pubertas agar para siswa dapat lebih memahami tentang perubahan-perubahan yang terjadi pada masa pubertas supaya dapat menerima dengan baik.

3. Bagi tenaga kesehatan

Dapat dijadikan bahan kajian untuk lebih mengintensifkan lagi penyuluhan mengenai pengetahuan tentang sikap remaja awal tentang perubahan fisik pada masa pubertas.

\section{DAFTAR PUSTAKA}

1. Bambang. Faktor-Faktor Yang Berhubungan dengan Perilaku Remaja terhadap Kesehatan Reproduksi Siswa Paket B Setara SMP PKBM BIM Kota Depok Jawa Barat. Skripsi : Fakultas Kesehatan Masyarakat Universitas Indonesia; 2015.

2. Astuti A. Hubungan frekuensi fastfood dan status gizi dengan usia menarche dini pada siswi sekolah dasar di SDN 1 Kleco, SDN 15 dan SDN Bumi 1 di Surakarta. Skripsi: Universitas Muhammadiyah Surakarta. 2014. Tersedia dalam: http://eprints.ums.ac.id/.Diakses tanggal: 24 Oktober 2018

3. Kusmiran E. Kesehatan Reproduksi Remaja dan Wanita. Jakarta: Salemba Medika; 2011

4. Marmi. Kesehatan Reproduksi. Yogyakarta: Pustaka Pelajar; 2015

5. Mardiyah S. Hubungan Antara Tingkat Pengetahuan Tentang Perubahan Fisik Pada Masa Pubertas dengan Konsep Diri Remaja SMP Negeri 6 Yogyakarta. Jurnal: STIKes Kusuma Husada; 2016.Tersedia dalam: http://jurnalstikeskusumahusada.ac. id. Diakses 26 Oktober 2018.
6. Notoatmodjo S.Metodelogi Penelitian Kesehatan. Jakarta : Rineka Cipta; 2012

7. Dewi W. Teori dan Pengetahuan Sikap dan Prilaku Manusia. Yogyakarta: Nuha Medika; 2010.

8. Indahyani F. Ilmu Sikap dalam Psikologi. Jurnal: FKIP UMP.; 2015.Diakses 28 Oktober 2018.

9. Nirwana BA. Psikologi Kesehatan Wanita. Yogyakarta: Nuha Medika; 2011

10. Hamidah. Hubungan Pengetahuan dengan Sikap Remaja Putri dalam Menghadapi Menarche di SMPN 2 Biau Kabupaten Buol. Jurnal: Unismuh $\quad$ Palu; 2018. http://jurnal.unismuhpalu.ac.id. 